\section{Response to 'Risk of systemic lupus erythematosus in patients with idiopathic thrombocytopenic purpura' by Xie and Zhang}

We thank Xie et al for their relevant comments on our recent article in the Annals of Rheumatic Disease entitled 'Risk of systemic lupus erythematosus in patients with idiopathic thrombocytopenic purpura: a population-based cohort study'. ${ }^{1}$ We are pleased that this correspondence allows us to provide additional data and further discussion to explain these comments.

Our study aimed to investigate the risk of new-onset of systemic lupus erythematosus (SLE) in patients with new diagnosis of idiopathic thrombocytopenic purpura (ITP) in the setting of claim-based National Taiwan Insurance Research Database. To ensure that we included only new cases, we excluded subjects with previous diagnosis of ITP or SLE to avoid the possibility of pre-existing SLE. All the International Classification of Diseases, Ninth Revision, Clinical Modification codings were defined by at least three ambulatory visits or one hospitalisation, as validated in previous studies. ${ }^{2}{ }^{3}$ We agree that some patients with ITP might have had subclinical or even underdiagnosed clinical SLE when ITP was diagnosed. Unfortunately, the serological data, such as antinuclear antibody, were not available in our dataset.

To further clarify this bias, we did time-varying effect to show the adjusted HR (aHR) indifferent time intervals (table 1). We agree that within 3 years of ITP diagnosis, the incredible high HR might be due to pre-existing or overlapping subclinical SLE. However, we also found that even when ITP has been diagnosed for 5-10 years, the risk of incidental SLE is still significantly high (aHR=13.0, 95\% CI 3.4 to 50 ). For this group for 'late-onset' SLE, it is unlikely to be preexisting SLE in patients with ITP.

For second comment about the incidence of SLE, the incidence of SLE in the non-ITP control group in our study was 2.1 (95\% CI 1.4 to 3.1) per 100000 person-months; convert to 25.2 per 100000 person-years. It is similar to the North American study data, which was 23.2/100000 person-years (95\% CI 23.4 to 24.0$).{ }^{4}$ We surely agree that there might be underdiagnosed subjects who have no diagnosis coding by rheumatologists or who are not even seeking medical visits in this claim-based dataset. However, considering the long follow-up period of our study of up to 14 years, we think this underdiagnosis rate is relatively low and should not change the results.

Finally, we agree that there are always residuals confounding in a retrospective real-world study. In this study, although smoking and family history data were unavailable, we had done extensive matching by frequency matching and propensity score on possible confounders and proxy comorbidities to improve baseline comparability of both groups. ${ }^{5}$ Many possible confounding diseases, including rheumatoid arthritis, Sjogren's syndrome, systemic sclerosis, vasculitis, hypertension, diabetes mellitus, hyperlipidaemia, coronary artery disease, osteoporosis, cerebral vascular accident, asthma, chronic obstructive pulmonary disease, chronic kidney disease, chronic liver disease, hyperthyroidism, thyroiditis, pancreatitis and antiphospholipid antibody syndrome were thus matched or adjusted to minimise this bias. Furthermore, we also did four models of sensitivity tests to confirm the consistent results.
Table 1 Incidence of SLE in ITP and non-ITP populations

Before PSM

(1:20 age-sex matching)

\begin{tabular}{ll}
\hline Non-ITP & ITP \\
$n=14460$ & $n=723$
\end{tabular}

\begin{tabular}{|c|c|c|}
\hline \multicolumn{3}{|l|}{ Between 1 and 6 months } \\
\hline Follow-up person-months & 57677 & 2812 \\
\hline $\operatorname{SLE} / n(\%)^{*}$ & $2 / 14460(0.01)$ & $10 / 723(1.38)$ \\
\hline Incidence ratet $(95 \% \mathrm{Cl})$ & $3.4(0.87$ to 13.9$)$ & 355.6 (191.3 to 660.9$)$ \\
\hline aHR $(95 \% \mathrm{Cl})$ & Reference & 64.0 (11.2 to 366.9$)$ \\
\hline \multicolumn{3}{|l|}{ Between 6 months and 1 year } \\
\hline Follow-up person-months & 57185 & 2673 \\
\hline $\mathrm{SLE} / \mathrm{n}(\%)^{*}$ & $2 / 14,53(0.01)$ & $6 / 684(0.88)$ \\
\hline Incidence ratet $(95 \% \mathrm{Cl})$ & 3.5 (0.9 to 14.0$)$ & 224.5 (100.9 to 499.6) \\
\hline aHR $(95 \% \mathrm{Cl})$ & Reference & 78.7 (13.2 to 467.1$)$ \\
\hline \multicolumn{3}{|l|}{ Between 1 and 3 years } \\
\hline Follow-up person-months & 286432 & 12694 \\
\hline $\mathrm{SLE} / \mathrm{n}(\%)^{*}$ & $7 / 14,243(0.05)$ & $8 / 657(1.22)$ \\
\hline Incidence ratet $(95 \% \mathrm{Cl})$ & $2.4(1.2$ to 5.1$)$ & $63.0(31.5$ to 126.0$)$ \\
\hline $\mathrm{aHR}(95 \% \mathrm{Cl})$ & Reference & $33.8(10.0$ to 113.9$)$ \\
\hline \multicolumn{3}{|l|}{ Between 3 and 5 years } \\
\hline Follow-up person-months & 236662 & 9934 \\
\hline $\operatorname{SLE} / n(\%)^{*}$ & $6 / 11,884(0.05)$ & $8 / 514(1.56)$ \\
\hline Incidence ratet $(95 \% \mathrm{Cl})$ & 2.5 (1.1 to 5.6$)$ & 80.5 (40.3 to 161.0$)$ \\
\hline aHR $(95 \% \mathrm{Cl})$ & Reference & $22.4(6.2$ to 81.2$)$ \\
\hline \multicolumn{3}{|l|}{ Between 5 and 10 years } \\
\hline Follow-up person-months & 421787 & 17031 \\
\hline $\mathrm{SLE} / \mathrm{n}(\%)^{*}$ & 8/9742 (0.08) & $4 / 399(1.00)$ \\
\hline Incidence ratet $(95 \% \mathrm{Cl})$ & 1.9 (1.0 to 3.8$)$ & 23.5 (8.8 to 62.6$)$ \\
\hline aHR $(95 \% \mathrm{Cl})$ & Reference & $13.0(3.4$ to 50.0$)$ \\
\hline
\end{tabular}

Median follow-up time, ITP=67 months and non-ITP=89 months.

${ }^{*} n$, number of individuals at risk at the beginning during the period. tIncidence rate, per 100000 person-months.

aHR, adjusted HR; PSM, propensity-score matching; SLE, systemic lupus erythematosus.

In conclusion, compared with previous studies that are small sample sizes or cross-sectional, our 14 years' population-based big data cohort study demonstrated that patients with ITP are at a higher risk of subsequent SLE. Clinically, patients with ITP should be educated and monitored for the risk of incidental SLE.

Fang-Xiao Zhu, ${ }^{1}$ Jing-Yang Huang, ${ }^{2,3}$ Qing-Qing Wen, ${ }^{1}$ James Cheng-Chung Wei $\circledast^{3,4,5}$

${ }^{1}$ Department of Rheumatology and Immunology, The Second Affiliated Hospital of Guilin Medical University, Guilin, China

${ }^{2}$ Department of Medical Research, Chung Shan Medical University Hospital, Taichung City, Taiwan, Taiwan

${ }^{3}$ Institute of Medicine, Chung Shan Medical University, Taichung, Taiwan ${ }^{4}$ Department of Allergy, Immunology and Rheumatology, Chung Shan Medical University Hospital, Taichung, Taiwan

${ }^{5}$ Graduate Institute of Integrated Medicine, China Medical University, Taichung, Taiwan

Correspondence to Dr James Cheng-Chung Wei, Institute of Medicine, Chung Shan Medical University, Taichung, Taiwan; jccwei@gmail.com

Handling editor Josef S Smolen

Funding The present study was supported by the Programme of Scientific andTechnology Project (Guilin Science Research and Technology Development, grant number 2016012706-2)

Competing interests None declared.

Patient and public involvement Patients and/or the public were not involved in the design, conduct, reporting or dissemination plans of this research. 
Patient consent for publication Not required.

Provenance and peer review Commissioned; internally peer reviewed.

(C) Author(s) (or their employer(s)) 2020. No commercial re-use. See rights and permissions. Published by BMJ.

\section{(D) Check for updates}

To cite Zhu F-X, Huang J-Y, Wen Q-Q, et al. Ann Rheum Dis Epub ahead of print: [please include Day Month Year]. doi:10.1136/annrheumdis-2020-217694

Received 28 April 2020

Accepted 28 April 2020

\section{SLinked}

- http://dx.doi.org/10.1136/annrheumdis-2020-217659

Ann Rheum Dis 2020:0:1-2. doi:10.1136/annrheumdis-2020-217694

\section{ORCID iD}

James Cheng-Chung Wei http://orcid.org/0000-0003-0310-2769

\section{REFERENCES}

1 Zhu F-X, Huang J-Y, Ye Z, et al. Risk of systemic lupus erythematosus in patients with idiopathic thrombocytopenic purpura: a population-based cohort study. Ann Rheum Dis 2020. doi:10.1136/annrheumdis-2020-217013

2 Shen T-C, Tu C-Y, Lin C-L, et al. Increased risk of asthma in patients with systemic lupus erythematosus. Am J Respir Crit Care Med 2014;189:496-9.

3 Shi L-H, Huang J-Y, Liu Y-Z, et al. Risk of systemic lupus erythematosus in patients with human papillomavirus infection: a population-based retrospective cohort study. Lupus 2018;27:2279-83

4 Rees F, Doherty M, Grainge MJ, et al. The worldwide incidence and prevalence of systemic lupus erythematosus: a systematic review of epidemiological studies. Rheumatology 2017;56:1945-61.

5 Yong S-B, Su K-W, Chen H-H, et al. Impact of chronic urticaria on systemic lupus erythematosus: a nationwide population-based study in Taiwan. J Dermatol 2019;46:26-32. 